\title{
EXPOSURE TO OCCUPATIONAL-RELATED BLOOD AND FLUIDS INFECTIONS, ACCIDENTAL INJURIES AND PRECAUTION PRACTICES AMONG HEALTHCARE WORKERS IN A TERTIARY HOSPITAL IN SOUTH- WEST, NIGERIA
}

\author{
Adetoun A. Oyekunle ${ }^{1 *}$, Olanrewaju A. Idowu' ${ }^{2}$, Temidayo O. Awvioro², \\ and Oluwasayo B. Ogunlade (Ph.D) ${ }^{3}$
}

${ }^{1}$ Postgraduate student, School of Nursing, Faculty of Health Sciences, University of Botswana. ${ }^{2}$ Clinical Nurse/Clinical Instructor, Obafemi Awolowo University Teaching Hospitals Complex, IleIfe. Nigeria.

${ }^{3}$ Department of Nursing Science, College of Health Sciences, Obafemi Awolowo University, Ile- Ife, Nigeria

*Correspondence E-mail: adetounwunmi@yahoo.com

Cite this article:

Adetoun A.O., Olanrewaju A.I., Temidayo O.A., Oluwasayo B.O. (2021), Exposure to Occupationalrelated Blood and Fluids Infections, Accidental Injuries and Precaution Practices among Healthcare Workers in a Tertiary Hospital in South-West, Nigeria. African Journal of Health, Nursing and Midwifery 4(6), 43-59. DOI: 10.52589/AJHNMZUHMCMEB

\section{Manuscript History}

Received: 3 Oct 2021

Accepted: 23 Oct 2021

Published: 18 Nov 2021

Copyright $\odot 2020$ The Author(s). This is an Open Access article distributed under the terms of Creative Commons Attribution-NonCommercialNoDerivatives 4.0 International (CC BY-NC-ND 4.0), which permits anyone to share, use, reproduce and redistribute in any medium, provided the original author and source are credited.
ABSTRACT: Background and Aim: Healthcare workers are at risk of infections from blood-borne pathogens due to percutaneous injuries from sharps, mucous membrane and skin exposures to contaminated blood and bodily fluids. The study, therefore, investigated exposure to occupational-related blood and fluids infections, accidental injuries and precaution practices among health care workers in a tertiary hospital in South-West, Nigeria. Methods: The study utilised a crosssectional research design requiring a structured questionnaire to elicit data from medical doctors, nurses and laboratory scientists/technologists. Through the convenience sampling technique, 266 respondents were selected for the study. Non-parametric descriptive statistics were used to analyse the data with the level of significance of the chi-square test put at 5\%. Results: The overwhelming majority ( $76 \%)$ of the health care workers at the hospital are of the female gender. The study found that the majority of the respondents (92\%) were trained on infection control in the course of their career while virtually all of them (98\%) had never contracted an occupational-related infection. Recapping of used needles accounted for $24.4 \%$ of activity that predisposed the workers to accidental injuries. Also, there was a significant association between the recapping of needles and the occurrence of accidental injuries $(P . V .=$ 0.000). Meanwhile, the incidence of unreported injuries stood at $70.3 \%$ as all the reasons given were significant $(P . V .=0.000)$ using a onesample chi-square test. Conclusion: It has been established that prevention practices like training in infection control, adherence to clear work procedures and guidelines, post-exposure prophylaxis and use of personal protective equipment were associated with contraction of occupational-related infections. Moreover, while recapping of used needles was a usual practice in the hospital, it was, however, associated with cases of accidental injuries among most health care workers. Unfortunately, most cases of injuries were unreported due to certain significant reasons.

KEYWORDS: Occupational Infection, Blood and Body Fluids, PostExposure Prophylaxis, Recapping, Un-reported injuries. 


\section{INTRODUCTION}

Healthcare workers (HCWs) are at risk of occupational exposure to blood-borne pathogens through contact with human blood and body fluids. Exposure to blood and body fluids is one of the most prevalent hazards among healthcare workers. It has been noted that every working day, over 59 million HCWs in the world run the risk of getting infected with hepatitis, Human Immuno Virus (HIV) and tuberculosis by accidental exposure to patients' blood and other body fluids. ${ }^{20}$ A report in 2005, estimated that more than 3 million job-related percutaneous injuries occurred annually. It was also documented that about $2.5 \%$ of HIV infections and roughly $40 \%$ of Hepatitis-B Virus (HBV) and Hepatitis-C Virus (HCV) infections occurring among healthcare workers are due to percutaneous injury. Hence, each year, the percutaneous injury resulted in around $66000 \mathrm{HBV}$ infections, $16000 \mathrm{HCV}$ infections and $1000 \mathrm{HIV}$ infections, which together caused about 1100 fatalities as well as a substantial disability. ${ }^{5}$ Similarly, nearly 160 health care workers retire annually as a result of infections acquired through occupational transmission. Specifically, it has been approximated that 503,000 piercing and cutting injuries occurred in the United States; out of which, 385,000 happened in hospital settings. On an annual basis, it is also estimated that 100,000 sharp injuries occur in the United Kingdom while about 500,000 needle stick injuries were recorded in German hospitals. ${ }^{35}$ However, the global estimate shows that about $90 \%$ of occupational exposures occurred in developing countries where the risk was under-appreciated, overlooked, and poorly prevented. ${ }^{35}$

Occupational exposure in this context can be described as any percutaneous injury such as a needle stick prick, or a cut through a sharp object. It could also be the contact of non-intact skin or mucous membrane with infected body fluids, blood or tissue at the workplace. ${ }^{23}$ However, injuries through occupational exposure were believed to be under-reported; often, half of the incidents were never reported. Different studies have established that healthcare workers were at risk of exposure to blood and body fluids and other forms of percutaneous injuries with a very high percentage not reporting the incident. A cross-sectional survey study was conducted in seven hospitals among healthcare workers in Iraq and the finding showed that more than half of the study participants reported at least one percutaneous and mucosal exposure to blood and fluid. ${ }^{16}$ In Ethiopia also, a descriptive cross-sectional institution-based study reported a high prevalence of occupational exposure among healthcare workers. ${ }^{6}$ In some developing countries, few studies are showing a clear picture of the incident report of exposure to blood and body fluids among healthcare workers. However, a cross-sectional study done in northern Nigeria found that exposure to blood and body fluids are most common among primary health care workers, with the majority of the respondents not reporting the incident of the exposure. ${ }^{25}$ Another study conducted in southern Nigeria also reported that more than half of the number of the healthcare workers failed to report incidences of exposure to blood and body fluids in the course of their duty. ${ }^{18}$

Health workers have been recognised as having an increased risk of infection, owing to their occupational exposure to blood and body fluids, particularly in the absence of appropriate infection prevention and control, and occupational health and safety measures. ${ }^{34}$ The aforementioned studies established that exposure of healthcare workers to blood and body fluids occurs in every part of the world, and this exposure poses a serious occupational health risk to healthcare workers. Occupational exposure to blood-borne pathogens, particularly hepatitis B and C or HIV, can result in debilitating or fatal disease, and even when PostExposure Prophylaxis (PEP) is timely and useful, treatments have severe health and economic consequences. ${ }^{30}$ The risk of blood-borne infections through occupational exposure among 
healthcare workers in developing countries such as Nigeria is very high. This is a result of a relatively high prevalence of these blood pathogens in the community and limited or nonavailability of personal protective equipment. According to studies from three tertiary hospitals in Nigeria, it was observed that most of the healthcare workers were exposed to needle stick injuries; a similar proportion $\left(75.8 \%\right.$ ) of them were exposed to blood and body fluids. ${ }^{15}$ These results are comparable with the $68 \%$ found in another tertiary hospital in southwest Nigeria. ${ }^{4}$ ${ }^{25}$ Therefore, the high prevalence of exposure of healthcare workers to blood and body fluids have been seen to be because of lack of knowledge and lack of implementation of safety policies in the health institutions in Nigeria. ${ }^{26}$

Furthermore, a Nigeria-based study revealed that most healthcare workers are at risk of exposure to blood and body fluids through needle stick injuries and blood splash. ${ }^{25}$ Consequently, a study linked healthcare workers' exposure to the improper disposal of needles.

4 To this end, a group of authors with reference to a study in Kaduna state, Nigeria recommended the need to establish a surveillance system for registering, reporting and managing occupational injuries and exposures in order to increase occupational safety for healthcare workers. ${ }^{25}$ This reinforces the advocacy of the International Labor Convention demanding that employers provide a comprehensive safety programme that anticipates workrelated risks and specifies strategies for protection against occupational injuries and infections. Such a precautionary approach is recommended in future planning, especially where evidence regarding transmission is incomplete. ${ }^{32}$.

The catalogue of studies reviewed shows that there is a risk of exposure to blood and body fluids infections among healthcare workers. It is still imperative to unravel those factors responsible for the under-reporting of incidents of exposure to infections and accidental injuries due to the recapping of used needles across different cadres of the workforce in the hospital. Therefore, this research is designed to investigate the prevalence of occupational exposure to blood and body fluids, the incidence of accidental injuries and factors responsible for underreporting of incidences of the injuries related to the exposure to blood and body fluids among the healthcare workers.

Moreover, it was documented that some healthcare workers were exposed to occupational hazards characterised by HIV infection, albeit dependent on certain factors like professional status, working room and timely use of personal protective equipment. ${ }^{6}$ Also, a related study in Saudi Arabia reported a high prevalence of exposure to blood and body fluids as a challenge among nurses. ${ }^{33} \mathrm{~A}$ group of authors have equally associated the prevalence or incidence of needle-stick and sharp injuries with exposure to blood and body fluids among healthcare workers (HCWs) in developing countries. ${ }^{22}$ An Ethiopian hospital has shown an estimate of $66 \%$ exposure to Blood and Body Fluids (BBF) among healthcare workers. ${ }^{37}$. This is in agreement with another finding from a Serbian hospital that documented the same exposure to BBF. ${ }^{20}$ In addition, it has been established that the average number of episode exposures to BBF among health care workers accounted for 66.3/100 annually. ${ }^{38}$

In the case of Africa, with particular reference to Nigeria, the incidence of exposure to infections among healthcare workers remains a very disturbing challenge. According to a couple of studies among healthcare workers from two tertiary hospitals in north-central and south-southern Nigeria, there was reportedly a high degree of exposure to BBF through contact with patients, needle pricks, cuts by sharps and splash from the mucous membrane. ${ }^{27} 26$. A group of authors assessed the extent of work-related exposure to blood and body fluids and 
associated factors among health workers and identified non-use of protective devices, lack of infection-prevention training, anti-infection Hepatitis B Virus (HBV) vaccination and recapping of used needles as risk factors for BBFs splash exposure. ${ }^{39}$

Healthcare workers are usually vulnerable to accident incidence in the discharge of their duties due to several activities. A study was carried out in Ethiopia involving medical personnel in public hospitals and the authors found a $46 \%$ prevalence of at least one occurrence of percutaneous injury in the preceding year. However, it was noticed that only $24 \%$ received prophylaxis against the human immune deficiency virus (HIV). Further findings from the same study revealed that the respondents who recapped needles were more vulnerable to percutaneous injuries while educational qualification was noted as a correlational factor for exposure to needle stick or sharp injuries. Meanwhile, nurses and cleaners were also at increased risk for the occurrence of percutaneous injuries ${ }^{19}$. It has equally been noted that needle recapping, not following infection prevention guidelines and lack of injection safety training influenced significantly needle-stick and sharp injury occurrence. ${ }^{1}$

In terms of the attitude of healthcare workers towards reporting of incidence of accidental injury relating to the handling of blood and body fluids, findings from the literature are mixed. It is quite curious that a study revealed that albeit most healthcare workers were exposed to needle-stick injuries as well as blood splash, under-reporting of exposure incidences still remains a big challenge. ${ }^{25}$ Meanwhile, a group of scholars averred that the most common reasons for non-reported or under-reported cases were attributed to perceived lack of time and low risk of transmission. ${ }^{36}$ Similarly, a study among healthcare workers in Ethiopia documented that nearly three-fifths $(58.7 \%)$ of injuries related to sharps were not reported to the concerned authority as a result of time constraints as well as lack of knowledge that it ought to be reported. ${ }^{9}$. In a recent study carried out among medical interns in Nigeria, the high prevalence of exposure to $\mathrm{BBF}$ was documented and the major reason for not reporting exposure was a lack of awareness of reporting systems and procedures. ${ }^{28}$. In contrast, a study in West Indies reported the majority of the healthcare workers to be aware of policies and procedures for reporting accidents while the majority of the respondents experienced splashes from body fluids. It was also found in the same study that most of the medical doctors and nurses had experienced needlestick injuries, while the incidence among medical technologists was remarkably lower. Moreover, the authors revealed that the majority of the respondents had a low experience of accident incidence while most of them had received post-exposure treatment. ${ }^{40}$

Courtenay-Quirk et al. in a study involving canvassing a need for occupational post-exposure prophylaxis in Sub-Saharan Africa found that most health facilities did not have the formal standard operating procedure (SOP) for reporting exposure to blood and other percutaneous injuries. ${ }^{41}$ In this context, some authors suggested appropriate measures to minimise the risks of occupational exposure to BBF which include the need for training in standard precautions, training on infection control and prevention. The suggestion further entails the use of personal protective equipment, training of medical staff on post-exposure prophylaxis with emphasis on timely reporting of exposures, proper safety protocols, encouraging voluntary reporting and active surveillance. ${ }^{31} 352123$. In addition, a group of scholars opined with regards to policy guidelines that all health facilities should have a written injection safety policy and a postexposure prophylaxis protocol, to manage all aspects of risk perception and practices of Healthcare Workers (HCWs), who should be continually educated on them. ${ }^{3}$. In the view of Julius, Salamat, Bukola, Joshua and Deborah, non-availability of personal protective 
equipment, lack of regular training on precautions and lack of good policy on standard precautions were significant factors for contracting occupational infections and injuries. ${ }^{42}$

In another development, Enwere and Diwe conducted a study among healthcare workers in a tertiary health institution in the South-Eastern part of Nigeria. Among other findings, the authors reported that the majority of the respondents have had a previous needle prick injury while only a handful of them received post-exposure prophylaxis. ${ }^{14}$ Similarly, it has been discovered that accidental needle-stick injuries were more prevalent during operations on patients in the theatre. Meanwhile, according to Bhardwaj, Sivapathasundaram, Yusof, Minghat, Swe and Sinha, most healthcare workers received vaccination against hepatitis B. ${ }^{43}$ Similarly, Bekele, Gebremariam, Kaso and Ahmed noted a low prevalence of needle stick and sharp injury among healthcare workers in Southeast Ethiopia. The authors also established a relationship between needle recapping on one hand, and needle stick and sharp injury on the other hand. ${ }^{8}$

In a related study, a high prevalence of needle stick and sharp injury among HCWs was documented. Specifically, it was noted that consistent availability of sharp storage coupled with waste disposal containers were significant predictors of needle stick and sharp injuries. ${ }^{7}$ Bekele, A group of scholars revealed in their study that more than half of the healthcare workers did not report accident incidence relating to injury due to time constraints and lack of knowledge of reporting procedures. ${ }^{8}$ Moreover, a study was carried out in Ghana titled, "Occupational Exposure to Needle Stick Injuries among Healthcare Workers at the Tamale Teaching Hospital". In this study, the author found that activities like recapping needles after use and suturing were associated with needle stick injuries. Meanwhile, almost half of the injured respondents did not report their injuries. ${ }^{17}$ Equally, sharp-related hospital injuries have been associated with recapping and inappropriate disposal of medical wastes. The medical literature further reported that most of the medical workers received anti-hepatitis B vaccination while a few of them experienced needlestick injuries. ${ }^{11}$ Similarly, the needle stick injuries were associated with the recapping device. On the other hand, the most usual reason for the un-reported incidents of injuries was the fear of being blamed or getting sanctioned. ${ }^{29}$

Abadiga, Mosisa and Abate assessed needle-stick and sharp injuries and associated factors among nurses working at health institutions in western Ethiopia, 2020. In this study, a high magnitude of injuries resulting from sharps was noted. However, less than half of the respondents had experienced needle-stick and sharp injuries in the 12 months preceding the study. Meanwhile, activities like needle recapping, non-compliance with infection prevention guidelines and not taking injection safety training were significant factors for getting needlestick and sharp injuries. Furthermore, a study noted a prevalence of about half of the sharp injury among the healthcare workers' studies. But only $24 \%$ took prophylaxis for Human Immune Deficiency Virus (HIV) infection. ${ }^{1}$ Also, another study revealed that needle recapping was a predictor of percutaneous injury. ${ }^{19}$ In a nutshell, it has been clearly established in the literature that injuries relating to needle sticks are a recurring decimal among most healthcare workers across various hospitals and health institutions. However, under-reporting or nonreporting of accidental injuries relating to the handling of sharps remains a disturbing behaviour among health professionals as noted in the selected published articles reviewed for this study. 


\section{METHODS}

\section{Research Design}

The study adopted a cross-sectional design to investigate exposure to BBF, the occurrence of occupational-related infection, accidental injuries related to recapping and reasons for unreported injury cases at Obafemi Awolowo University Teaching Hospital (OAUTH) in Osun State, South-West, Nigeria.

\section{Study Population}

The study respondents were those healthcare workers involved in direct patient care and at the same time potentially at risk of contact with Blood and Body Fluids (BBFs). This category of workers selected included medical doctors, nurses and laboratory scientists/technologists/technicians. Those who consented to participate among the aforementioned workers were included in the study as respondents. In terms of description, the hospital is a first-generation health facility established by the Federal Government of Nigeria. It is an 800-bed specialised referral hospital rendering tertiary healthcare services; located along the Ife-Ilesha express road in Ife Central Local Government Area of Osun state. The institution has six units, namely: Ife Hospital Unit, Ile-Ife, Wesley Guild Hospital, Ilesha, Dental Hospital OAU, Ile-Ife, Urban Comprehensive Health Centre, Eleyele, Ile-Ife, Rural comprehensive health Centre, Imesi-Ile, and Multi-purpose Maternal and Child Health Centre, Ilesha respectively.

\section{Sample Size Determination}

The sample size was determined using Cochran's formula $(\mathrm{n}=\mathrm{Z} 2 \mathrm{pq} / \mathrm{d} 2)$ (Cochran, 1977). ${ }^{12}$ Where: $\mathrm{Z}=1.96, \mathrm{p}=$ prevalence of occupational exposure to BBF in a previous study of $68 \%$ ${ }^{25}, \mathrm{~d}=5 \%$ of marginal error. This yielded a sample size of 384 .

\section{Sampling}

Through the convenience sampling technique, 266 healthcare workers from the hospital were selected as respondents to take part in the study in order to elicit vital information from them.

\section{Data Collection Instrument}

A semi-structured questionnaire was used to elicit data from the respondents. The instrument was structured into three parts to include the consent form, the socio-demographics and information related to exposure to BBFs, the occurrence of accidental injuries and reasons for unreported injury cases. The reliability of the instrument was extracted after the Cronbach's Alpha test yielded a value of approximately 93\%. Meanwhile, an expert in the field of Public Health and Biostatistics was contacted to validate the contents in order to ensure face and content validity prior to the administration of the instrument.

\section{Method of Data Collection}

The respondents were first briefed at an individual level about the aim of the study by the authors and the role expected of them in filling out the copies of the questionnaire. The questionnaire copies were distributed to them individually at various points in time and retrieved accordingly after they were filled. Those who needed further clarifications regarding 
their role in the study were given adequate attention. In all, a total of 384 copies of the questionnaire were administered on them but 266 copies duly filled were returned and subsequently used for the analysis. The data collection exercise lasted between July and September 2019.

\section{Method of Data Analysis}

The data were presented using frequency counts, percentages, pie charts, cross-tabulations and chi-square to test the hypothesised association between recapping of needles after use and accidental injuries; and reasons for un-reported injuries. Meanwhile, the level of significance was pre-determined at a 5\% level. The analysis was facilitated by the deployment of IBMSPSS version 23.0 software.

\section{Ethical Considerations}

Although the study did not involve the collection of samples like tissues, organs, blood, urine, saliva and other body fluids from the respondents, the author ensured that the ethical principles of confidentiality, anonymity, non-malfeasance and voluntarism were rigidly adhered to during the study in tandem with Helsinki World Medical declaration.

\section{RESULTS AND DISCUSSION}

Table 1: Socio-Demographic Attributes of the Respondents

\begin{tabular}{lll}
\hline Variable Category & Frequency (266) & Percentage (100) \\
\hline Gender & - & - \\
Male & 64 & 24.1 \\
Female & 202 & 75.9 \\
Educational Qualification & - & - \\
Diplomas & 138 & 51.9 \\
Bachelor Degrees & 113 & 42.5 \\
Master Degrees & 14 & 5.3 \\
Doctorate Degrees & 1 & 4 \\
Professional category & - & - \\
Nurse & 219 & 82.3 \\
Doctor & 19 & 7.1 \\
Lab technicians/technologists & 28 & 10.5 \\
Years of service & - & - \\
1-5years & 177 & 66.5 \\
6-10years & 38 & 14.3 \\
11-15years & 34 & 12.8 \\
16-20years & 7 & 2.6 \\
>=21years & 10 & 3.8 \\
Daily work hours & - & - \\
5-8Hrs per day & 174 & 65.4 \\
$>$ 8 Hrs per day & 92 & 34.6 \\
\hline SOurce: Field & &
\end{tabular}

Source: Field work, 2019 
The socio-demographic attributes of the healthcare workers at Obafemi Awolowo University Teaching Hospital Complex (OAUTHC) are presented in Table 1 above. The background information shows that the overwhelming majority $(76 \%)$ of the sampled workforce is of the female gender while most of them $(52 \%)$ possessed diploma certificates. It could be inferred that those with diploma certificates were likely to be nurses and medical laboratory scientists. Similarly, the teaching hospital was dominated by the nurses who accounted for $82 \%$ with the doctors having the proportion of $7 \%$. This reveals a gross shortage of medical doctors in such a third-tier health facility that provides healthcare services to the public as well as clinical training for the medical students. This situation could also mirror the lamentable plight of Nigerians in terms of the doctor-to-patient ratio, thereby restricting access to healthcare services. Meanwhile, those who had spent between 1-5years constituted the majority of the health workers $(66.5 \%)$ in the facility. Furthermore, $3.8 \%$ of them had spent 21 years and above working in the facility. The daily work time schedule of the health workers indicated that more than half of them $(65.4 \%)$ spent 5-8 hours per day working.

\section{Table 2: Distribution by Preventive Practices towards Contracting Occupational- related Infection}

\begin{tabular}{|c|c|c|c|}
\hline \multirow{2}{*}{\multicolumn{2}{|c|}{ Infection prevention practices }} & \multicolumn{2}{|c|}{$\begin{array}{l}\text { Ever contracted occupational-related } \\
\text { infection related to BBF }\end{array}$} \\
\hline & & Yes & No \\
\hline \multirow{2}{*}{$\begin{array}{l}\text { Received } \\
\text { professional training } \\
\text { in infection control }\end{array}$} & Yes $245(92.1 \%)$ & $6(2.4 \%)$ & $260(97.7 \%)$ \\
\hline & No $21(7.9 \%)$ & & \\
\hline \multirow[t]{2}{*}{$\begin{array}{l}\text { Given clear work } \\
\text { procedures/guidelines }\end{array}$} & $\begin{array}{l}\text { Yes } 224 \\
(84.2 \%)\end{array}$ & $6(2.7 \%)$ & $218(97.3 \%)$ \\
\hline & No $42(15.8 \%)$ & & \\
\hline \multirow{2}{*}{$\begin{array}{l}\text { Ever sought for post- } \\
\text { exposure prophylaxis }\end{array}$} & Yes $55(20.7 \%)$ & $6(2.3 \%)$ & $260(97.7 \%)$ \\
\hline & No $211(79.3 \%)$ & & \\
\hline \multirow{3}{*}{$\begin{array}{l}\text { Personal protective } \\
\text { equipment adequate } \\
\text { for use }\end{array}$} & $\begin{array}{l}\text { Yes } 225 \\
(84.6 \%)\end{array}$ & $6(2.3 \%)$ & $260(97.7 \%)$ \\
\hline & No $41(15.4 \%)$ & & \\
\hline & No $109(41.0 \%)$ & & \\
\hline
\end{tabular}

Source: Authors' computation Using SPSS version 23 software.

From Table 2 above, the author examined the relationship between contraction of occupationalrelated infection and prevention practices among the healthcare workers in Obafemi Awolowo University, Ife, Osun State using cross-tabulations. The result revealed that the majority of the respondents $(92 \%)$ were trained on infection control in the course of their career while virtually all of them $(98 \%)$ had never contracted an occupational-related infection. The finding is at variance with a study carried out by Yasin et al. who noted a lack of infection-prevention training as a risk factor for contracting an infection through blood splash. ${ }^{39}$ However, it could be deduced that there was no relationship between infection control training received and ever contracted occupational-related infection. Similarly, those who were given clear work 
procedures and guidelines accounted for more than half of the respondents (84\%) as compared to a very sizeable number $(97 \%)$ that had never had contracted an occupational-related infection. It can be reported that there was no relationship between the healthcare workers that ever sought post-exposure prophylaxis and those who never contracted the infection at the hospital. This is indicated by the fact that a handful of about $21 \%$ sought post-exposure prophylaxis while most of them $(97.7 \%)$ acted otherwise. However, this finding contrasts with the study conducted by Vaz et al. who noted a high (60\%) uptake of post-exposure treatment. ${ }^{40}$ Again, the low uptake of the post-exposure recorded in this current study might be attributed to inadequate provision of the vaccines. However, the finding is in tandem with some other previous studies that reported low uptake of postexposure prophyl axis among healthcare workers.

14431939

Also, the availability and the adequate use of the personal protective equipment shows a sort of association with contraction of occupational infection. This is indicated in the crosstabulation where the healthcare workers that had not contracted occupational infection accounted for the majority of the respondents $(97.7 \%)$ in relation to most of them $(84.6 \%)$ that confirmed the adequate use of the protective devices. This is consistent with Julius et al. (2021) who identified non-availability of personal protective equipment, lack of regular training on precautions and lack of good policy on standard precautions were significant factors for contracting occupational infections.

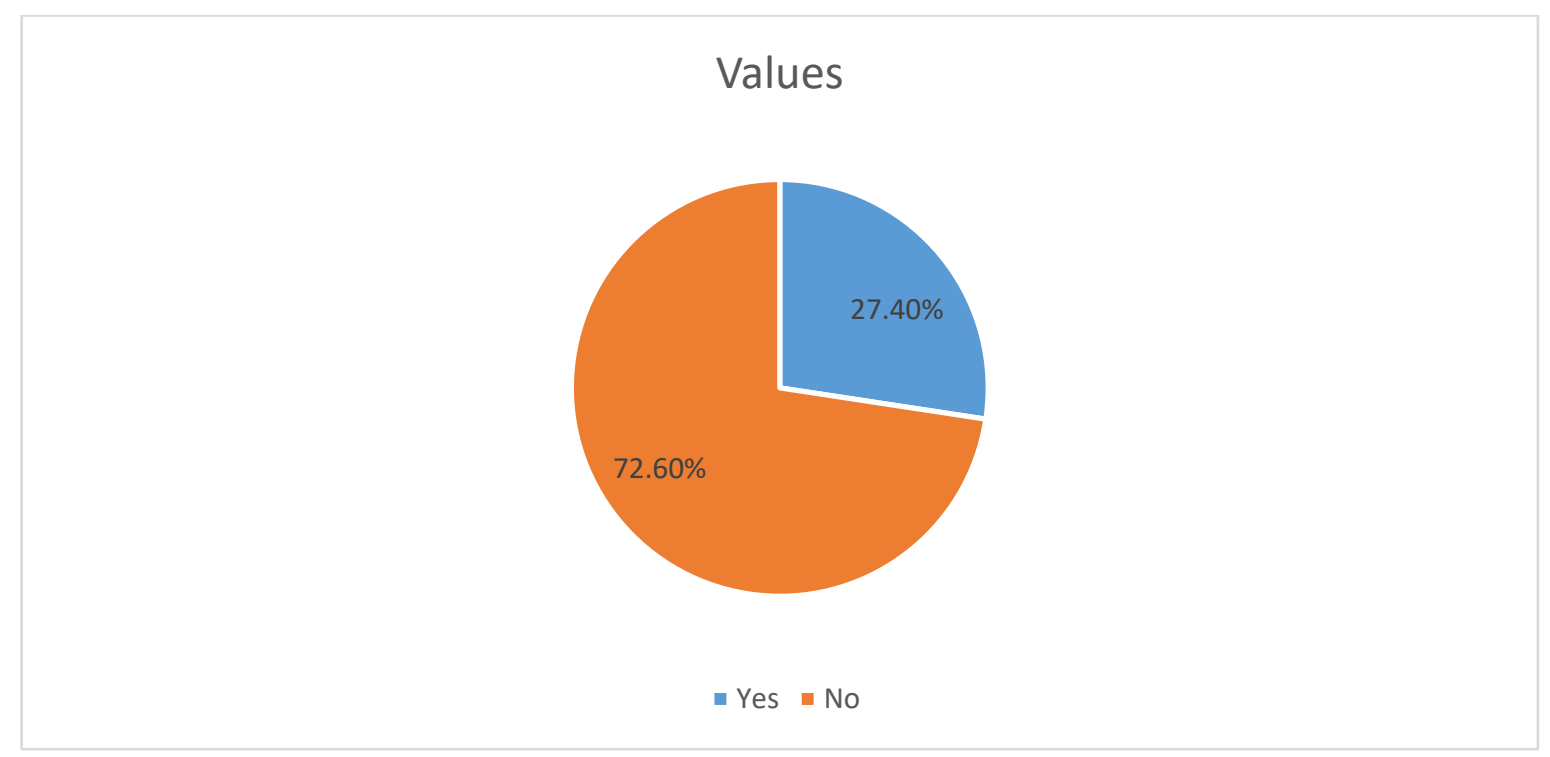

Figure 1: Pie Chart Showing Percentages Distribution of Recapping of Needles among HCWs

Recapping of used needles is a regular practice among HCWs. To this end, the HCWs in the hospital were asked whether they recapped needles after use. The responses presented above using a pie chart shows that out of 266 respondents, the larger proportion (73.6\%) recapped needles after use. However, recapping of needles has been associated with accidental needle stick injuries. 
Table 3: Association between Recapping of Needles after Use and Accidental Injury

\begin{tabular}{lrr}
\hline & \multicolumn{2}{c}{ Recapping of } \\
Needles after Use & Accidental injury related to recapping of needles \\
\hline Chi-Square & $54.135^{\mathrm{a}}$ & $16.376^{\mathrm{a}}$ \\
Df & 1 & 1 \\
Asymp. Sig. & .000 & .000 \\
\hline
\end{tabular}

Source: Field work, 2019

The chi-square test result in Table 3 shows that there is a significant association between the recapping of needles after use and the occurrence of accidental injuries related to the handling of blood and body fluids using needles. This is underscored by the fact that the chi-square value of 54.135 has a corresponding probability value of 0.000 less than the 0.05 level of significance. Based on this outcome, the a priori assumption that recapping of needles did not have a significant association with the occurrence of an accidental injury is hereby set aside. However, the finding agrees with certain studies in the literature. For example, Kaweti and Abegaz noted that needle recapping after use was associated with the occurrence of percutaneous injury. ${ }^{19}$ Similarly, several studies have reaffirmed the relationship between the recapping of needles and accidental injuries among healthcare workers. 119171 Almost all the previous studies, including the current one appear to be unanimous that recapping of needles in hospitals by healthcare workers is a very high-risk factor for experiencing accidental injuries.

Table 4: Percentage Distribution of Respondents by Accident-causing Activities

\begin{tabular}{lll}
\hline Work Activities & Frequency (266) & Percentage (100\%) \\
\hline Recapping & 65 & 24.4 \\
Disposal & 35 & 13.1 \\
Suturing & 16 & 6.0 \\
Cutting & 47 & 17.7 \\
Child delivery & 45 & 16.9 \\
Sharps in an unexpected area & 38 & 14.2 \\
Collections from receptacles & 20 & 7.5 \\
\hline
\end{tabular}

Source: Field work, 2019

Apart from recapping used needles, other activities in the hospital predispose healthcare workers to accidental injuries relating to the handling of blood and body fluids. Table 4 shows the occurrence of accidental injuries being attributable to recapping as the most common activity and it accounted for $24.4 \%$. This was followed by cutting (17.7\%) and child delivery $(16.9 \%)$ respectively. The least injury-induced activity among the respondents represented about $8 \%$. 
Table 5: Percentage Distribution of Respondents by Accidental Sharp-induced injury

\begin{tabular}{llll}
\hline & & $\begin{array}{l}\text { Frequency } \\
(\mathbf{2 6 6})\end{array}$ & $\begin{array}{l}\text { Percentage } \\
(\mathbf{1 0 0})\end{array}$ \\
\hline $\begin{array}{l}\text { Ever encountered } \\
\text { accident/risk related } \\
\text { handling of BBF. }\end{array}$ & Yes & 166 & 62.4 \\
& Mild & 100 & 37.6 \\
Classify accident/risk & Moderate & 82 & 30.8 \\
encountered & Severe & 31 & 57.5 \\
No of times ever had & 0 time & 48 & 11.7 \\
accident/risk within & 1-2 times & 159 & 18.0 \\
last 12 months. & $3-4$ times & 32 & 59.8 \\
& $5-10$ times & 6 & 12.0 \\
& $>10$ times & 21 & 2.3 \\
Report the accident/ & Yes & 79 & 7.9 \\
incidence that & No & 187 & 70.3 \\
occurred. & Yes & 125 & 47.0 \\
& No & 38 & 14.3 \\
& I don't know & 103 & 38.7 \\
\cline { 2 - 4 } & &
\end{tabular}

Source: Field work, 2019

In discharging their duties in the hospital, occasions usually warrant doctors, nurses and laboratory technicians/technologists to transfuse blood to patients, extract blood and other body fluids for diagnostic analysis. If proper care is not taken, either the blood or body fluids might splash on the medical personnel. In this study, Table 5 shows that the majority of the medical personnel (62.4\%) have had an accident /risk related to the handling of Blood and Body Fluids (BBF) while giving healthcare services. At this point, it suffices to state that exposure to blood and body fluid among healthcare workers remains a very big challenge in health care service delivery. Also, the medical personnel were asked to give a classificatory description of the accident/risk related ever had in the handling of BBF and more than half of the respondents $(57.5 \%)$ considered it as moderate while the minority (11.7) described it as severe. Similarly, those who experienced incidents/accidents/risks due to infections from sharps, needle pricks, cuts, bruises, abrasion, blood splash and glove tear in the last 12 months preceding this study accounted for a significant $59.8 \%$ of the respondents. However, only a few of them $(29.7 \%)$ reported the accident incidence that occurred with the majority $(70.3 \%)$ un-reported. This is quite curious as the reasons for the un-reported occurrence of accident incidence in the hospital have been tracked and presented in table 6 below. The table also shows that less than half of the respondents (47\%) affirmed the existence of standard guidelines for reporting accidental exposure to blood and body fluids in the hospital while approximately $39 \%$ did not know. 
Table 6: Respondents' Distribution by Reasons for Un-reported Accident Incidence

\begin{tabular}{lll}
\hline & Frequency (266) & $\begin{array}{l}\text { Percentage } \\
(\mathbf{1 0 0})\end{array}$ \\
\hline Self-care & 154 & 57.8 \\
Fear of punishment & 13 & 4.9 \\
Low infection risk & 66 & 24.8 \\
Time constraint & 10 & 3.8 \\
Belief in self-sufficient vaccination & 9 & 3.4 \\
Lack of knowledge & 14 & 5.3 \\
& & \\
\hline
\end{tabular}

Source: Field Work, 2019.

In alignment with Table 2, the majority of the respondents that ever had accident incidence related to the handling of blood and body fluids failed to report it for some obvious reasons. Table 6 shows that more than half of them (57.8\%) embarked on self-care and so did not deem it fit to report accident incidence. For fear of being punished by the hospital management, $4.9 \%$ failed to report the incidence while $24.8 \%$ believed that their exposure to infection was low, hence no need to report it. The aforementioned reasons are in consonance with a previous study finding. ${ }^{29}$ Furthermore, other reasons adduced for the un-reporting of accident incidence included time constraint $(3.8 \%)$, belief in self-sufficient $(3.4 \%)$ vaccination and lack of knowledge $(5.3 \%)$.

Table 7: One-Sample Chi-square Test of Reasons for Un-reported Injuries

\begin{tabular}{llll}
\hline \multicolumn{1}{c}{ Null Hypothesis } & Test & Sig. & Decision \\
Categories of reasons for & One- & & Reject the \\
unreported accidental injuries. & sample & .000 & null \\
1. Accidental injury occurrence & Chi-square & & hypothesi \\
with equal probabilities. & Test & & $\mathrm{s}$
\end{tabular}

Source: Authors' Computation Using SPSS Version 23

The on-sample chi-square test results in Table 7 shows that all the reasons given in Table 7 are significantly associated with un-reported accident incidence in the hospital among the HCWs. This is indicated by the 0.000 probability value of the chi-square less than 0.05 level of significance. In other words, reasons such as self-care; fear of punishment; low infection risk; time constraint; belief in self-sufficient vaccination; and lack of knowledge of accident reporting standards has a significant association with un-reported accident incidence. This finding is in alignment with a literature publication that associated lack of time and low risk of transmission with non-reported or under-reported cases of accidental injuries. ${ }^{36}$ It also reinforces a couple of previous studies that identified time constraints as well as lack of 
awareness of reporting systems and procedures as reasons for un-reported accidental injuries. 928

\section{Policy Implications of the Findings}

The hospital management board should organise periodic training and retraining on infection control protocols and procedures for the healthcare workers comprising mostly, medical doctors, nurses and laboratory scientists/technologists. This should be reinforced by setting up an infection control monitoring team that will ensure compliance with the protocols. Also, postexposure prophylaxis should be made available by the management for the staff in need to access it. This should be coupled with creating awareness about its necessity for the workers to take. Since recapping of used needles is a regular practice in the hospital, the workers should be retrained on the practice to minimise the high cases of accidental injuries resulting from the practice.

As it has been advocated, this study reaffirmed that the management should conduct seminars and workshops aimed at sensitising the healthcare workers on the need for timely reporting of infection exposures and accidental injuries. Workers who summon the courage to report occurrences of accidental injuries should not be sanctioned but empathised with. This will encourage other potential victims to imbibe the culture of early reporting of exposures and accidental injuries.

\section{Strength and Limitation}

The study has been able to offer empirical information towards the pursuit of the Sustainable Development Goal (SDG) 8 which borders among others, the promotion of full and productive employment as well as decent work for all. It has also unravelled the non-clinical reasons behind un-reported accidental injuries among healthcare workers. The findings arising from this study can be generalised to all the tertiary hospitals in Nigeria. Despite the inherent strengths of the study, a couple of limitations were associated with it due to the non-capturing of other healthcare workers like cleaners, security personnel and drivers that work in the hospital setting. These categories of health workers may also be vulnerable to contracting infections and encountering accidental risk, though not necessarily related to recapping and handling of BBFs.

\section{CONCLUSION}

It has been established that prevention practices like training in infection control, adherence to clear work procedures and guidelines, post-exposure prophylaxis and use of personal protective equipment were associated with contraction of occupational-related infections. Moreover, while recapping of used needles was a usual practice in the hospital, it was, however, associated with cases of accidental injuries among most health care workers as noted in this study. Unfortunately, most cases of injuries were un-reported due to certain significant reasons like lack of awareness of the reporting system and procedures, time constraints and fear of being sanctioned by the hospital management. 


\section{REFERENCES}

[1]. Abadiga M, Mosisa G, Abate Y. Magnitude of Needlestick and Sharp Injury and its Associated Factors among Nurses Working at Health Institutions in Western Ethiopia, 2020. Risk Management and Healthcare Policy 2020; 13:1589-1602.

[2]. Abere G, Yenealem DG, Wami SD. Occupational Exposure to Blood and Body Fluids among Health Care Workers in Gondar Town, Northwest Ethiopia:

A Result from Crosssectional Study. Journal of Environmental and Public Health 2020; 19. https://doi.org/1 $\underline{0.1155 / 2020 / 3640247 .}$

[3]. Akinboro AA, Adejumo OP, Onibokun CA, Olowokere EA. Community healthcare workers' risk perception of occupational exposure to HIV in Ibadan, South-west Nigeria. African Journal of Primary Health Care \& Family Medicine 2012; 4(1).

[4]. Amira C, Awobusuyi, J. Needle-stick injury among health care workers in hemodialysis units in Nigeria: a multi-centre study. The International Journal of Occupational and Environmental Medicine 1 January 2014; 5(228):221-228.

[5]. Auta A, Adewuyi EO, Tor-Anyiin A, Aziz D, Ogbole E, Ogbonna BO, Adeloye D. Health-care workers' occupational exposures to body fluids in 21 countries in Africa: Systematic review and meta-analysis. Bulletin of the World Health Organisation 2017; 95 (12):831-841F.

[6]. Aynalem Tesfay F, Dejenie Habtewold T. Assessment of prevalence and determinants of occupational exposure to HIV infection among healthcare workers in selected health institutions in Debre Berhan town, North Shoa Zone, Amhara Region, Ethiopia, 2014. AIDS research and treatment 2014, 2014.

[7]. Bazie GW. Factors Associated with Needle Stick and Sharp Injuries among Healthcare Workers in North East Ethiopia. Risk Management and Healthcare Policy 2020; 13:2449-2456.

[8]. Bekele T, Gebremariam A, Kaso M, Ahmed K. Attitude, reporting behaviour and management practice of occupational needlestick and sharps injuries among hospital healthcare workers in Bale zone, Southeast Ethiopia: a cross-sectional study. Journal of Occupational Medicine and Toxicology 2015; 10(42):1-7.

[9]. Bekele T, Gebremariam A, Kaso M, Ahmed K. Factors Associated with Occupational Needle Stick and Sharps Injuries among Hospital Healthcare Workers in Bale Zone, Southeast Ethiopia. PLOS ONE 2015; 10(10):1-11. doi:10.1371/journal.pone.0140382.

[10]. Bhardwaj A, Sivapathasundaram N, Yusof MF, Minghat AH, Swe KMM, Sinha NK. The Prevalence of Accidental Needle Stick Injury and their Reporting among Healthcare Workers in Orthopaedic Wards in General Hospital Melaka, Malaysia. Malaysia Orthopaedic Journal 2014; 8(2):6-13. http://dx.doi.org/10.5704/MOJ.1407.009.

[11]. Bi P, Tully PJ, Boss K, Hiller JE. Sharps Injury and Body Fluid Exposure among Health Care Workers in an Australian Tertiary Hospital. Asia-Pacific Journal of Public Health 2008; 20(2): 139-147.

[12].Cochran WG. Sampling Techniques: 3 ed, Wiley New York. 1977. Courtenay-Quirk C, Selenic D, Lahuerta M, Kassa G, Murrman M, Bock N. Development of an Intervention to Increase Occupational Postexposure Prophylaxis in Sub-Saharan Africa. Journal of the Association of Nurses in AIDS Care 2016; 27(5):727-730. 
[13]. Engeda EH. Incident Reporting Behaviours and Associated Factors among Nurses Working in Gondar University Comprehensive Specialized Hospital, Northwest Ethiopia. Scientifica 2016; 1-7. http://dx.doi.org/10.1155/2016/6748301.

[14]. Enwere OO, Diwe KC. (2014). Knowledge, perception and practise of injection safety and healthcare waste management among teaching hospital staff in south-east Nigeria: an intervention study. Pan African Medical Journal 2014; 1 (218): 15. doi:10.11604/pamj.2014.17.218.3084.

[15]. Holla R, Unnikrishnan B, Ram P, Thapar R, Mithra P, Kumar N., . . . Darshan BB. (2014). Occupational Exposure to Needle Stick Injuries among Health Care Personnel in a Tertiary Care Hospital: A Cross-Sectional Study. J Community Med Health Educ 2014, 2: 004.

[16]. Hosoglu S, Ahmad Z, Tahseen MS, Diyar Z, Selbes S, Çolak A. (2014). High incidence of occupational exposures among healthcare workers in Erbil, Iraq. Journal of Infection in Developing Countries 2014; 8(10):1328-1333. doi:10.3855/jidc.4280.

[17]. Ibrahim I. Occupational Exposure to Needle Stick Injuries among Health Care Workers at the Tamale Teaching Hospital. School of Public Health, College of Health Sciences, University Of Ghana. Unpublished M.Sc dissertation 2015; 1-61.

[18]. Isara A, Oguzie K, Okpogoro O. Prevalence of needlestick injuries among healthcare workers in the Accident and Emergency Department of a Teaching Hospital in Nigeria. Annals of medical and health sciences research 2015; 5(6):392-396.

[19]. Kaweti G, Abegaz T. Prevalence of percutaneous injuries and associated factors among health care workers in Hawassa referral and Adare District hospitals, Hawassa, Ethiopia, January 2014. BMC Public Health 2016; 16(8):1-7.

[20]. Mandic B, Mandic-Rajcevic S, Markovic-Denic L, Bulat P. Occupational exposure to blood and bodily fluids among healthcare workers in Serbian general hospitals. Arhiv Za Higijenu Rada I Toksikologiju-Archives of Industrial Hygiene and Toxicology 2018; 69(1):61-68.

[21]. Mashoto KO, Mubyazi GM, Mushi AK. Knowledge of occupational exposure to HIV: a cross-sectional study of healthcare workers in Tumbi and Dodoma Hospitals, Tanzania. BMC Health Services Research 2015; 15(1): 29.

[22]. Mehrdad R, Atkins E, Sharifian S, Pouryaghoub G. Psychosocial factors at work and blood-borne exposure among nurses. The International Journal of Occupational and Environmental Medicine 1 January 2014; 5(361): 332-369.

[23]. Mponela MJ, Oleribe OO, Abade A, Kwesigabo G. Post-exposure prophylaxis following occupational exposure to HIV: a survey of health care workers in Mbeya,

Tanzania, 2009-2010. Pan African Medical Journal 2015; 21(1).

[24]. Nderitu EW, Mill J, Richter S. The experience of Ugandan nurses in the practice of universal precautions. Journal of the Association of Nurses in AIDS Care 2015; 26(5):625-638.

[25]. Nmadu AG, Sabitu K, Joshua IA. Occupational exposure to blood and body fluids among primary health-care workers in Kaduna State, Nigeria. Journal of Medicine in the Tropics 2016; 18(2):79.

[26]. Ogoina D, Pondei K, Adetunji B, Chima G, Isichei C, Gidado S À propos Prevalence and determinants of occupational exposures to blood and body fluids among health workers in two tertiary hospitals in Nigeria. African journal of infectious diseases 2014; $8(2): 50-54$. 
[27]. Olaleye AO, Ogundele OA, Awokola BI, Olatunya OS, Olaleye OA, Adeyanju T, Omisore AG. Occupational exposure to HIV and use of post-exposure prophylaxis in a general hospital in North Central, Nigeria. International journal of occupational safety and health 2013;3(1):11-17.

[28]. Paul NI, Jaja T, Opara PI. Occupational Exposure to Blood and Body Fluids among Interns in a Tertiary Hospital in Port Harcourt, Nigeria. Open Access Library Journal 2018; 5(04):1.

[29]. Pavithran VK, Murali R, Krishna M, Shamala A, Yalamalli M, Kumar AV. Knowledge, attitude, and practice of needle stick and sharps injuries among dental professionals of Bangalore, India. J Int Soc Prevent Community Dent. 2015, 5:406-12.

[30]. Quinn MM, Markkanen PK, Galligan CJ, Kriebel D, Chalupka SM, Kim H., . . . Davis L. Sharps injuries and other blood and body fluid exposures among home health care nurses and aides. American journal of public health 2009, 99(S3): S710-S717.

[31]. Rajkumari N, Thanbuana B, John NV, Gunjiyal J, Mathur P, Misra MC. A prospective look at the burden of sharps injuries and splashes among trauma health care workers in developing countries: True picture or tip of the iceberg. Injury 2014; 45(9):1470-1478.

[32]. Ringen K, Landrigan PJO, Stull J, Duffy R, Melius J, McDiarmid MA. Occupational safety and health protections against Ebola virus disease. American journal of industrial medicine 2015; 58(7):703-714.

[33]. Samargandy SA, Bukhari LM, Samargandy SA, Bahlas RS, Aldigs EK, Alawi MA., ... Madani TA. Epidemiology and clinical consequences of occupational exposure to blood and other body fluids in a university hospital in Saudi Arabia. Saudi Medical Journal 2016; 37(7): 783-790. doi:10.15537/smj.2016.7.14261

[34]. Selvaraj SA, Lee KE, Harrell M, Ivanov I, Allegranzi B. Infection Rates and Risk Factors for Infection among Health Workers during Ebola and Marburg Virus Outbreaks: A Systematic Review. The Journal of infectious diseases 2018 November 22; 218(suppl_5): S679-S689. Doi:10.1093/infdis/jiy435.

[35]. De Souza-Borges FRF, Ribeiro LA, de Oliveira LCM. Occupational exposures to body fluids and behaviours regarding their prevention and post-exposure among medical and nursing students at a Brazilian Public University. Revista do Instituto de Medicina Tropical de São Paulo 2014; 56(2):157-163.

[36]. Voide C, Darling KE, Kenfak-Foguena A, Erard V, Cavassini M, Lazor-Blanchet, C. Underreporting of needle stick and sharps injuries among healthcare workers in a Swiss University Hospital. Swiss Med Wkly 2012; 142(0).

[37]. Yenesew MA, Fekadu GA. Occupational exposure to blood and body fluids among health care professionals in Bahir Dar town, Northwest Ethiopia. Safety and health at work 2014; 5(1):17-22.

[38]. Zhang M, Wang H, Miao J, Du X, Li T, Wu Z. Occupational exposure to blood and body fluids among health care workers in a general hospital, China. Am J Ind Med.2009 Feb; 52(2):89-98. Doi:10.1002/ajim.20645.

[39]. Yasin J, Fisseha R, Mekonnen F, et al. Occupational Exposure to blood and body fluids and associated factors among health care workers at the University of Gondar Hospital, Northwest Ethiopia. Environ Health Prev Med 24; 24. https://doi.org/10.1186/s12199019-0769-9. 
[40]. Vaz K, Mcgrowdwer D, Crawford T, Alexander-Lindo RL, Irving R. Prevalence of injuries and reporting of accidents among health care workers at the University Hospital of the West Indies. Int J Occup Med Environ Health 2010; 23(2): 133-43. Doi:10.2478/v10001-010-0016-5.

[41]. Courtenay-Quirk C, Selenic D, Lahuerta M, Kassa G, Murrman M, Bock N. Development of an Intervention to Increase Occupational Post-exposure Prophylaxis in Sub-Saharan Africa. Journal of the Association of Nurses in AIDS Care 2016; 27(5):727-730.

[42]. Julius OM, Salamat OA, Bukola TM, Joshua OO, Deborah FO. Factors Influencing Standard Precaution Practices among Nurses in Lagos State University Teaching Hospital, Ikeja, Lagos State, Nigeria. African Journal of Health, Nursing and Midwifery 2021; 4(5):14-25. Doi:10.52589/AJHNM-IX3L8VO0.

[43]. Bhardwaj A, Sivapathasundaram MF, Yusof AH; Minghat KMM, Sinha NK. The prevalence of accidental needle stick injury and their reporting among health care workers in orthopaedic wards in general hospital Melaka, Malaysia. Malaysian orthopaedic journal 2014; 8(2). 